\title{
A Wide Diversity of Cortical GABAergic Interneurons Derives from the Embryonic Preoptic Area
}

\author{
Diego Gelman, ${ }^{1,2 \star}$ Amélie Griveau, ${ }^{3 \star}$ Nathalie Dehorter, ${ }^{1 \star}$ Anne Teissier, ${ }^{3}$ Carolina Varela, ${ }^{1}$ Ramón Pla, ${ }^{1}$ \\ Alessandra Pierani, ${ }^{3}$ and Oscar Marín ${ }^{1}$ \\ ${ }^{1}$ Instituto de Neurociencias, Consejo Superior de Investigaciones Científicas and Universidad Miguel Hernández, Sant Joan d'Alacant 03550, Spain, \\ 2Instituto de Investigaciones en Ingeniería Genética y Biología Molecular, Consejo Nacional de Investigaciones Científicas y Técnicas, Buenos Aires, \\ Argentina, and ${ }^{3}$ Institut Jacques-Monod, CNRS UMR 7592, Université Paris Diderot, Sorbonne Paris Cité, 75013 Paris, France
}

GABA-containing (GABAergic) interneurons comprise a very heterogeneous group of cells that are crucial for cortical function. Different classes of interneurons specialize in targeting specific subcellular domains of excitatory pyramidal cells or other interneurons, which provides cortical circuits with an enormous capability for information processing. As in other regions of the CNS, cortical interneuron diversity is thought to emerge from the genetic specification of different groups of progenitor cells within the subpallium. Most cortical interneurons originate from two main regions, the medial and the caudal ganglionic eminences (MGE and CGE, respectively). In addition, it has been shown that progenitors in the embryonic preoptic area (POA) also produce a small population of cortical GABAergic interneurons. Here, we show that the contribution of the POA to the complement of cortical GABAergic interneurons is larger than previously believed. Using genetic fate mapping and in utero transplantation experiments, we demonstrate that $D b x$ 1-expressing progenitor cells in the POA give rise to a small but highly diverse cohort of cortical interneurons, with some neurochemical and electrophysiological characteristics that were previously attributed to MGE- or CGEderived interneurons. There are, however, some features that seem to distinguish POA-derived interneurons from MGE- or CGE-derived cells, such as their preferential laminar location. These results indicate that the mechanisms controlling the specification of different classes of cortical interneurons might be more complex than previously expected. Together with earlier findings, our results also suggest that the POA generates nearly $10 \%$ of the GABAergic interneurons in the cerebral cortex of the mouse.

\section{Introduction}

Cortical GABAergic interneurons constitute one of the most diverse groups of cells in the CNS (Markram et al., 2004). The variety of cortical interneurons is so large, and their defining features so diverse, that it is difficult to reach a clear consensus

\footnotetext{
Received Aug. 3, 2011; revised Sept. 23, 2011; accepted Sept. 28, 2011.

Author contributions: D.G., A.G., N.D., A.T., C.V., R.P., A.P., and 0.M. designed research; D.G., A.G., N.D., A.T., C.V., and R.P. performed research; A.P. and O.M. contributed unpublished reagents/analytic tools; D.G., A.G., N.D., A.T., C.V., and R.P. analyzed data; D.G., A.G., N.D., C.V., A.P., and 0.M. wrote the paper.

This work was supported by grants from the European Commission through STREP contract number 005139 (INTERDEVO) to 0.M. and A.P.; the Spanish Ministry of Science and Innovation SAF2008-00770, SAF2009-08049-E, and CONSOLIDER CSD2007-00023 to 0.M.; and Fondation pour le Recherche Médicale (INE20060306503) and Ville de Paris (2006 ASES 102) to A.P. D.G. was recipient of a Marie Curie International Incoming Fellowship. A.G. was recipient of fellowships from the French Ministry of Education and the Association pour la Recherche sur le Cancer. N.D. is recipient of an EMBO Long Term Fellowship. A.T. was the recipient of a fellowship from the French Ministry of Education. A.P. is a CNRS Investigator. We thank M. Pérez, T.Gil, and A. Casillas for excellent technical assistance, and T. Jessell (Columbia University, NY), V. Pachnis (National Institute for Medical Research, Mill Hill, UK), J. L. R. Rubenstein (University of California San Francisco, CA), and F. H. Ruddle (Yale University) for antibodies and/or probes. We are very grateful to M. A. Valdeolmillos for sharing his electrophysiological set-up, and to R. Scott for helping to install the electrophysiology equipment in our laboratory and critical reading of the manuscript. We are also thankful to members from the Borrell, Marín, and Rico labs for stimulating discussions.

${ }^{*}$ D.G., A.G., and N.D. contributed equally to this work.

Correspondence should be addressed to Dr. Oscar Marín, Instituto de Neurociencias, CSIC and Universidad Miguel Hernández, Sant Joan d'Alacant 03550, Spain. E-mail: 0.marin@umh.es.

D. Gelman's present address: Instituto de Biología y Medicina Experimental, Consejo Nacional de Investigaciones Científicas y Técnicas, Buenos Aires, Argentina.

A. Griveau's present address: Eli and Edythe Broad Center of Regeneration Medicine and Stem Cell Research, University of California San Francisco, CA.

DOI:10.1523/JNEUROSCI.4068-11.2011

Copyright $\odot 2011$ the authors $\quad 0270-6474 / 11 / 3116570-11 \$ 15.00 / 0$
}

about their classification (Ascoli et al., 2008). Despite this complexity, increasing evidence suggests that cortical interneurons exist as distinct neuronal populations, which can be defined on the basis of their morphological, electrophysiological, and neurochemical characteristics (Freund and Buzsáki, 1996; DeFelipe, 1997; Kawaguchi and Kondo, 2002; Somogyi and Klausberger, 2005; Klausberger and Somogyi, 2008). The different classes of GABAergic interneurons specialize in targeting different subcellular domains of pyramidal cells or other interneurons, thereby modulating, in various manners, the activity of the different elements of cortical circuits (Klausberger and Somogyi, 2008).

The analysis of the developmental mechanisms underlying the generation of cortical interneuron diversity is perhaps one of the factors that has contributed extensively to the idea that cortical interneurons exist as distinct cell types. Based on extensive work in the spinal cord and hindbrain, it is now widely accepted that distinct cell types in the adult CNS derive from discrete populations of progenitor cells that express a unique code of transcription factors (Jessell, 2000; Lee and Pfaff, 2001; Dessaud et al., 2008). Accordingly, the specification of each class of interneurons is initially defined in progenitor cells by these transcriptional regulators, which impose the expression of a particular set of effector proteins (e.g., ion channels, calcium-binding proteins, etc). In other words, the laminar allocation or the intrinsic electrophysiological properties of a particular class of interneurons are likely to be determined at the time of neurogenesis or soon 
thereafter (Wonders and Anderson, 2006; Gelman and Marín, 2010).

In rodents, cortical GABAergic interneurons are born in several progenitor domains located in the subpallium and subsequently migrate toward the cortex, where they integrate into their final position (Anderson et al., 1997; Lavdas et al., 1999; Sussel et al., 1999; Wichterle et al., 1999; Corbin et al., 2001; Marín and Rubenstein, 2001; Nery et al., 2002). The medial ganglionic eminence (MGE) gives rise to several classes of interneurons that can be grouped into two broad categories: fast-spiking (FS) interneurons that express the calcium-binding protein parvalbumin (PV) and non-fast-spiking interneurons that contain the neuropeptide somatostatin (SST) (Xu et al., 2004; Butt et al., 2005; Fogarty et al., 2007; Miyoshi et al., 2007, 2010; Rubin et al., 2010). The caudal ganglionic eminence (CGE) also produces different classes of interneurons that belong to two large groups: bipolar interneurons that express vasoactive intestinal peptide (VIP) and/or the calcium-binding protein calretinin (CR), and multipolar interneurons that contain neuropeptide Y (NPY) or Reelin (López-Bendito et al., 2004; Xu et al., 2004; Butt et al., 2005; Lee et al., 2010; Miyoshi et al., 2010; Vucurovic et al., 2010).

Collectively, the MGE and the CGE are the origin of $>90 \%$ of the GABAergic interneurons in the cerebral cortex (Wonders and Anderson, 2006; Batista-Brito and Fishell, 2009; Rubin et al., 2010). Thus, one question that remains unsolved is the source of the remaining $\sim 10 \%$ of cortical interneurons that do not seem to derive from progenitor cells in the MGE and CGE. We have recently shown that the embryonic preoptic area (POA) is the source of a small population of cortical GABAergic interneurons (Gelman et al., 2009). Here, we have used genetic fate mapping and in utero transplantation experiments to trace the progeny of an additional distinct group of POA progenitor cells that are characterized by the expression of the transcription factor Dbx1. Our results demonstrate that this second pool of POA progenitor cells produces a small but highly diverse population of interneurons that primarily populate deep layers of the cortex. Altogether, these results indicate that the POA is the origin of nearly a tenth of the total population of cortical GABAergic interneurons.

\section{Materials and Methods}

Mouse lines. CD1 wild-type embryos were used for expression analyses and in utero transplantation experiments. Dbxl ${ }^{\text {Cre }}$ (Bielle et al., 2005), $D b \times 1^{n l s L a c Z}$ (Pierani et al., 2001), and ROSA26 ${ }^{\text {YFP }}$ (Srinivas et al., 2001) transgenic mice were generated and genotyped as previously described. For most experiments, $D b x 1^{C r e} ; R O S A 26^{Y F P /+}$ mice were crossed with ROSA2 $6^{\text {YFP/YFPP }}$ mice to generate Dbxi ${ }^{\mathrm{Cre}} ; \mathrm{ROSA}_{2} 6^{\mathrm{YFP} /+}$ or $\mathrm{Dbx} 1^{\mathrm{Cre}}$; ROSA $26^{Y F P / Y F P}$ animals at the appropriate stage. The day of vaginal plug was considered as embryonic day (E) 0.5. Animals were kept at the Instituto de Neurociencias de Alicante according to Spanish and European Union regulations.

In situ hybridization and immunohistochemistry. For in situ hybridization, embryonic brains were fixed overnight in $4 \%$ paraformaldehyde (PFA) and embedded in Tissue-Tek OCT compound (Sakura Finetek Europe). Frozen sections $(20 \mu \mathrm{m})$ were hybridized with digoxigeninlabeled probes as described previously (Flames et al., 2007). For immunohistochemistry, embryonic brains were fixed in $4 \% \mathrm{PFA}$ at $4^{\circ} \mathrm{C}$ for $2-6$ h. Brains were then embedded and cut frozen into $20 \mu \mathrm{m}$ sections in the cryostat or sectioned in the vibratome at $60 \mu \mathrm{m}$. Postnatal mice were anesthetized with an overdose of sodium pentobarbital and transcardially perfused with $4 \%$ PFA. Postnatal brains were removed, fixed for 1-3 $\mathrm{h}$ at $4^{\circ} \mathrm{C}$, and cryoprotected in $30 \%$ sucrose in PBS. Brains were then cut frozen on a sliding microtome at $40 \mu \mathrm{m}$. The following primary antibodies were used: rat anti-BrdU (1:100; Accurate), rabbit anti-calbindin (1: 3000; Swant), rabbit anti-CR (1:3000; Swant), rabbit anti-GABA (1:1000; Sigma), chicken anti-GFP (1:3000; Aves Labs), rabbit anti-Lhx6 (1:1000; kindly provided by V. Pachnis, National Institute for Medical Research, Mill Hill, UK), rabbit anti-NOS (1:1000; Immunostar), rabbit anti-NPY (1:1000; Millipore Bioscience Research Reagents), rabbit anti-PV (1: 5000; Swant), rat anti-SST (1:200; Millipore Bioscience Research Reagents), and rabbit anti-VIP (1:1000; Immunostar). The following secondary antibodies were used: goat anti-chicken 488, donkey antirabbit 555 (both from Invitrogen), and donkey anti-rat Cy3 (Jackson Laboratories). DAPI (Sigma) was used for fluorescent nuclear counterstaining. Dbx1-derived cells were mapped using a microscope equipped with Neurolucida software.

Transplantation experiments. In utero ultrasound-guided transplantation of POA-derived cells was performed as previously described (Pla et al., 2006) using E12.5 Dbx1 ${ }^{C r e} ; R_{O S A 26^{Y F P}}$ mouse embryos as donors. POA cells were dissected out from acute coronal slices through the telencephalon. Donor pregnant females were injected with BrdU $12 \mathrm{~h}$ before cesarean, and transplanted mice were analyzed at postnatal day (P) 14 .

Slice preparation and recordings. P17-23 Dbxi ${ }^{\text {Cre }} ;$ ROSA26 ${ }^{Y F P}$ mice were deeply anesthetized with isoflurane and decapitated. Brains were rapidly removed and placed in ice-cold oxygenated sucrose slicing solution containing the following (in $\mathrm{mM}$ ): 248 sucrose, $3 \mathrm{KCl}, 0.5 \mathrm{CaCl}_{2}, 4$ $\mathrm{MgCl}_{2}, 1.25 \mathrm{NaH}_{2} \mathrm{PO}_{4}, 26 \mathrm{NaHCO}_{3}$, and 10 glucose, saturated with $95 \%$ $\mathrm{O}_{2}$ and $5 \% \mathrm{CO}_{2}$. Coronal slices $(300 \mu \mathrm{m})$ were cut through the somatosensory cortex using a vibratome (Leica). The slices were then submerged in a warmed $\left(32^{\circ} \mathrm{C}\right)$ incubation chamber with artificial CSF (aCSF) containing the following (in mM): $124 \mathrm{NaCl}, 3 \mathrm{KCl}, 2 \mathrm{CaCl}_{2}, 1 \mathrm{MgCl}_{2}, 1.25$ $\mathrm{NaH}_{2} \mathrm{PO}_{4}, 26 \mathrm{NaHCO}_{3}$ and 10 glucose saturated with $95 \% \mathrm{O}_{2}$ and $5 \%$ $\mathrm{CO}_{2}$, for at least $30 \mathrm{~min}$ before recording, after which they were maintained at room temperature.

For patch-clamp recordings in whole-cell configuration, slices were transferred to the recording chamber of an upright Leica DMLFSA microscope coupled to a confocal spectral scanning head (Leica TCS SL) and viewed through a $20 \times$ water-immersion objective. Slices were continuously superfused with aCSF at $32^{\circ} \mathrm{C}$. Patch microelectrodes $(5-10$ $\mathrm{M} \Omega$ ) were pulled from borosilicate glass capillaries ( $1.5 \mathrm{~mm}$ outer diameter, 0.86 inner diameter; Harvard Apparatus) using a vertical P10 puller (Narishige) and filled with a potassium gluconate-based intracellular solution containing the following (in mM): $140 \mathrm{~K}$-gluconate, 10 HEPES, $2 \mathrm{NaCl}, 4 \mathrm{KCl}, 4 \mathrm{Mg}$-ATP, 0.4 Na-GTP, and 0.6 Alexa 555. Biocytin (2 $\mathrm{mg} / \mathrm{ml}$ ) was added for postrecording immunocytochemistry. For targeting POA-derived interneurons, yellow fluorescent protein (YFP)expressing cells were excited at $488 \mathrm{~nm}$. To visualize targeted cells in greater detail, a $543 \mathrm{~nm}$ laser beam was used to excite Alexa 555 dialyzed inside the recorded cells through the patch pipette. Interneurons were recorded in current-clamp configuration with an Axoclamp 200A amplifier (Molecular Devices) operating in a fast mode. Data were filtered on-line at $2 \mathrm{kHz}$ and acquired at a $20 \mathrm{kHz}$ sampling rate using pClamp 6.0.2 software (Molecular Devices). We estimated that approximately one-third of the YFP-expressing cells found in the cortex were glial cells. They were identified by their hyperpolarized resting membrane potential, low membrane resistance, and inability to fire action potentials $(n=20)$. Fluorescence was usually more intense in glial cells than in interneurons. Data from these cells were not included in the subsequent analysis.

The following parameters were rapidly measured after patching YFPexpressing interneurons or calculated from the average of three different measures for each cell (Gelman et al., 2009): resting membrane potential, membrane resistance, membrane conductance, spike threshold potential, action potential amplitude, duration of the action potential at its half amplitude, afterhyperpolarization (AHP) amplitude, maximum firing frequency [MFF; average frequency $(\mathrm{Hz})$ elicited by a $500 \mathrm{~ms}$ current injection], early firing frequency (first or second interspike interval), steady-state firing frequency (average of the last five interspike intervals), percentage of spike frequency adaptation (percentage of reduction between the first interspike frequency and the steady-state frequency), and delay to spike (measured from the beginning of the $500 \mathrm{~ms}$ step until the first spike at near threshold potential). Data analysis was performed offline with Clampfit 10.2. Cells with significant rundown were discarded. For the interneuron classification, we used the nomenclature proposed by the Petilla group (Ascoli et al., 2008) and Fishell and colleagues (Mi- 
yoshi et al., 2007, 2010; Lee et al., 2010). We considered a cell with a percentage of spike frequency adaptation $>25 \%$ as adapting and considered a cell delayed when duration between the beginning of the $500 \mathrm{~ms}$ step and the first spike at near threshold potential was $>125 \mathrm{~ms}$. The morphological reconstruction of recorded interneurons was performed using a microscope equipped with Neurolucida software.

Quantification. For the birth dating of cortical YFP-expressing cells, YFP/BrdU doublelabeled cells were counted from three animals at $\mathrm{P} 0$. These experiments were performed with two different reporter lines, with similar results. To examine some electrophysiological differences across populations, data were statistically analyzed using Student's $t$ tests. For the quantification of colocalization patterns, double-labeled cells were counted from four different sections throughout the rostrocaudal extent of the somatosensory cortex and from three different sections throughout the striatum. In all cases, data are expressed as mean \pm SEM.

\section{Results}

\section{A population of cortical GABAergic} interneurons derives from Dbx1-expressing progenitors

The transcription factor Dbx1 is expressed in restricted domains of the developing telencephalon, including the septum, the ventral pallium (VP), and the POA (Yun et al., 2001; Medina et al., 2004; Bielle et al., 2005; Flames et al., 2007). These progenitor cells give rise to neuronal populations that remain within the corresponding radial domains (Medina et al., 2004; Hirata et al., 2009), but also to tangentially migrating neurons that disperse through the telencephalon. For example, Dbx1-expressing cells located in the septum and the VP give rise to two different populations of Cajal-Retzius cells that populate the surface of the cortex (Bielle et al., 2005). The VP also seems to give rise to a transient population of glutamatergic cells that migrate tangentially to the neocortex (Teissier et al., 2010, 2011). In addition, it has been shown that the Dbx1-expressing progenitor cells located in the POA give rise to a unique population of GABAergic interneurons that populate the amygdala (Hirata et al., 2009).

A small population of Dbx1-derived cortical GABAergic interneurons has also been recently identified (Teissier et al., 2010), but the origin and properties of these cells remain uncharacterized. To study this population of neurons, we crossed $\mathrm{Db} \times 1^{\mathrm{Cre}}$ mice with the reporter strain ROSA26 ${ }^{Y F P}$ (Srinivas et al., 2001) and analyzed the distribution of YFP-expressing cells in P30 mice. We found scattered YFP-expressing cells distributed throughout the neocortex and hippocampus of $D b \times 1^{\text {Cre }}$; ROSA26 ${ }^{Y F P}$ mice (Fig. 1A). Although some of these cells had the typical morphology of glial cells (data not shown), many other YFP-expressing cells displayed characteristic neuronal morphol- ogies (Fig. 1 $A^{\prime}$ ). This later population of cells was particularly abundant in layers V and VI of the neocortex, although some cells with neuronal morphologies were also found in superficial layers (Fig. 1A). YFP-expressing cells were also found throughout the amygdala, striatum, and globus pallidus (data not shown). We performed double immunohistochemistry against YFP and GABA and found that most YFP-expressing cells in the cerebral cortex of P30 Dbx ${ }^{C r e} ;$ ROSA2 $6^{Y F P}$ mice were indeed GABAergic neurons $(67.4 \pm 3.2 \%, n=3$; Fig. $1 B-C$ "). Conversely, we found that YFP-expressing cells represent nearly $4 \%$ of the total amount of GABAergic neurons in the neocortex $(3.87 \pm 0.3 \%, n=4)$. Analysis of the laminar distribution of Dbx1-derived interneurons confirmed that the large majority of these cells occupy deep 


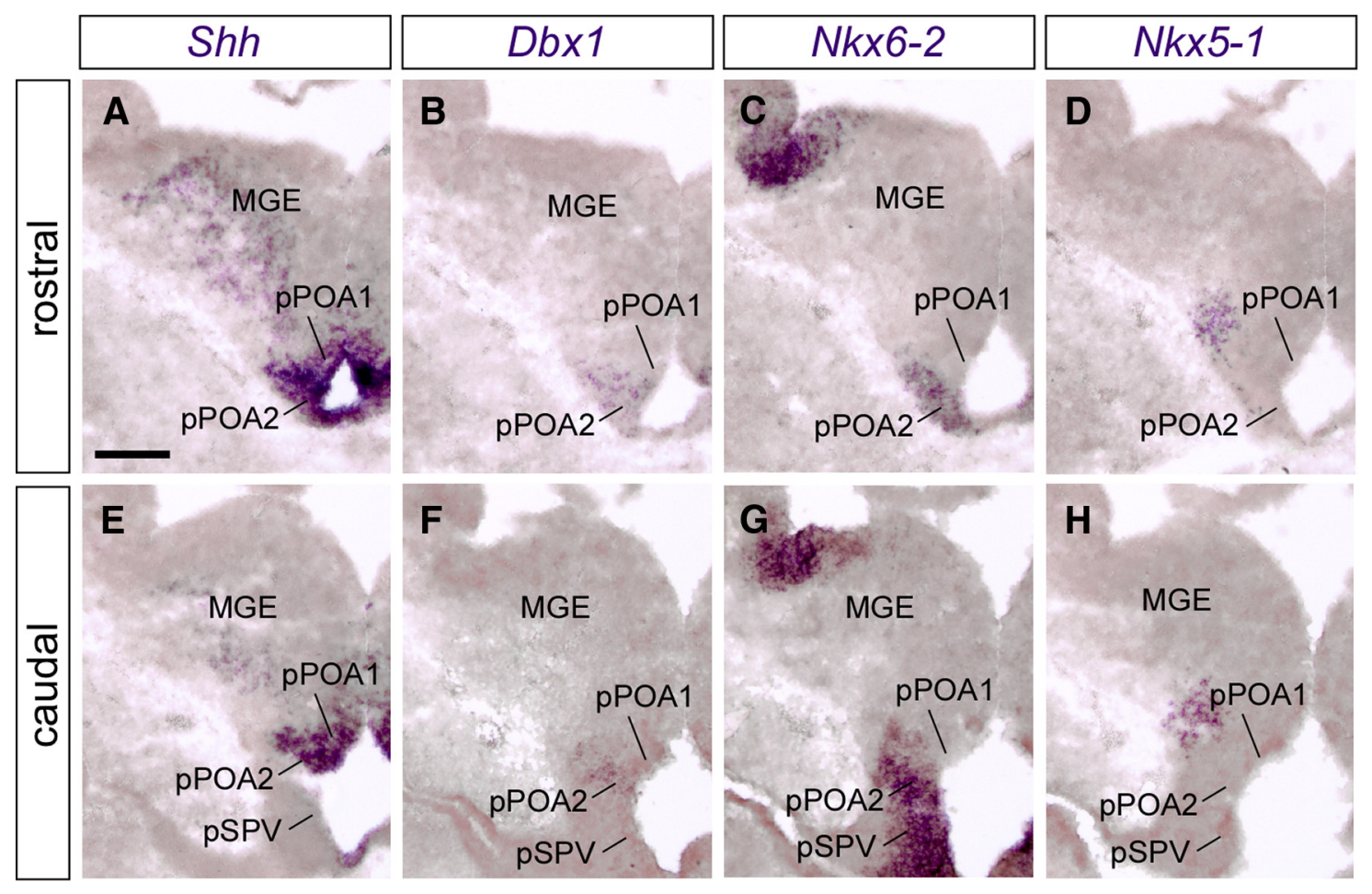

Figure 2. Molecular characterization of progenitor cells in the embryonic POA. $\boldsymbol{A}-\boldsymbol{H}$, Coronal sections through two different levels of the caudal telencephalon at E11.5 showing the expression of $\operatorname{Shh}(\boldsymbol{A}, \boldsymbol{E}), \operatorname{Dbx} 1(\boldsymbol{B}, \boldsymbol{F}), N k \times 6-2(\boldsymbol{C}, \boldsymbol{G})$, and $N k \times 5-1(\boldsymbol{D}, \boldsymbol{H})$ mRNA. In situ images $(\boldsymbol{A}, \boldsymbol{B})$ were pseudo-colored using Photoshop software. $\boldsymbol{A}-\boldsymbol{D}$ and $\boldsymbol{E}-\boldsymbol{H}$ are from the same brain and are adjacent to each other. pSPV, Supraoptic paraventricular progenitor domain. Scale bar, $100 \mu \mathrm{m}$.

layers of the neocortex ( $\sim 90 \%$ in layers V and VI; Fig. $1 D)$. Finally, we analyzed the birth date of Dbx1-derived cortical interneurons using BrdU analysis. We found that this population of interneurons is born at relatively early stages of neurogenesis within the subpallium, with nearly $80 \%$ of them being generated by E12.5 (Fig. $1 E$ ). In summary, these experiments revealed that the mouse cerebral cortex contains a population of early-born GABAergic interneurons that primarily populate deep layers of the neocortex and derive from Dbx1-expressing progenitor cells.

\section{The embryonic POA is the origin of Dbx1-derived cortical interneurons}

Previous studies have shown that the pallial Dbx1-expressing domains (septum and VP) generate glutamatergic neurons, and therefore are unlikely to produce GABAergic interneurons (Bielle et al., 2005; Wonders and Anderson, 2006; Griveau et al., 2010; Teissier et al., 2010). Moreover, recent experimental evidence indicates that the subpallial septum is not a source of cortical GABAergic interneurons (Rubin et al., 2010). In contrast, the POA has been previously shown to give rise to small populations of cortical and amygdalar GABAergic interneurons (Gelman et al., 2009; Hirata et al., 2009), which prompted us to analyze this region in more detail. Virtually all progenitor cells in the POA contain the transcription factor Nkx2-1 (Flames et al., 2007), and many of these cells also express Shh (Fig. 2A,E). We previously subdivided the embryonic POA into two distinct progenitor domains, pPOA1 and pPOA2, based on the expression of several transcription factors (Flames et al., 2007). We observed that pPOA2 contains at least two largely non-overlapping populations of progenitors that express $D b \times 1$ or $N k x 6-2$, while only scattered cells expressing these transcription factors are present in pPOA1 (Fig. $2 B, C, F, G$ ). Interestingly, the population of cells that was previously described to give rise to cortical interneurons in this region, characterized by the expression of $N k x 5-1$, seems to derive primarily from pPOA1 (Fig. $2 D, H$ ). This observation led us to hypothesize that the embryonic POA may give rise to several distinct population of interneurons, including one that derives from the pPOA1 and transiently expresses Nkx5-1 (Gelman et al., 2009), and another that presumably emerges from Dbx1-expressing progenitor cells in pPOA2.

We took advantage of a mouse strain that carries an insertion of $L a c Z$ [containing a signal peptide that targets $\beta$-galactosidase ( $\beta \mathrm{Gal}$ ) in the nucleus] in the $D b x 1$ gene to perform short-term lineage tracing experiments of cells derived from Dbx1expressing progenitors (Pierani et al., 2001). Analysis of the initial migratory trajectory of these cells revealed that many of them move toward the pallium as they leave the POA (Fig. $3 A-C$ ). Consistent with the theory that cortical interneurons derived from Nkx2-1-expressing territories downregulate the expression of this transcription factor soon after they start migrating toward the cortex (Nóbrega-Pereira et al., 2008), we found that many $\beta$ Gal-expressing cells that seem to migrate away from the POA do not contain Nkx2-1 (Fig. $3 C, D$ ), while $\beta$ Gal-expressing cells that remain within the POA coexpress Nkx2-1. In addition, $\beta \mathrm{Gal}-$ expressing cells in the POA were typically found to be negative for Nkx6-2 (Fig. 3C,D), although a few double-labeled cells were observed at caudal levels of the POA (data not shown).

Permanent tracing of Dbx1-derived cells in $\mathrm{Dbx}^{\mathrm{Cre}}$; ROSA $26^{Y F P}$ embryos confirmed that many of these cells seem to disperse from the POA toward the cortex between E11.5 and E15.5. In some rare cases, a few clones of YFP-expressing cells were also observed in the MGE, but the large majority of YFPexpressing cells were found to derive from the POA. Analysis of sagittal and horizontal sections through the telencephalon of E13.5 and E15.5 Dbxi ${ }^{\mathrm{Cre}} ; \mathrm{ROSA}_{26}{ }^{Y F P}$ embryos revealed several migratory streams that seem to link the embryonic POA with 


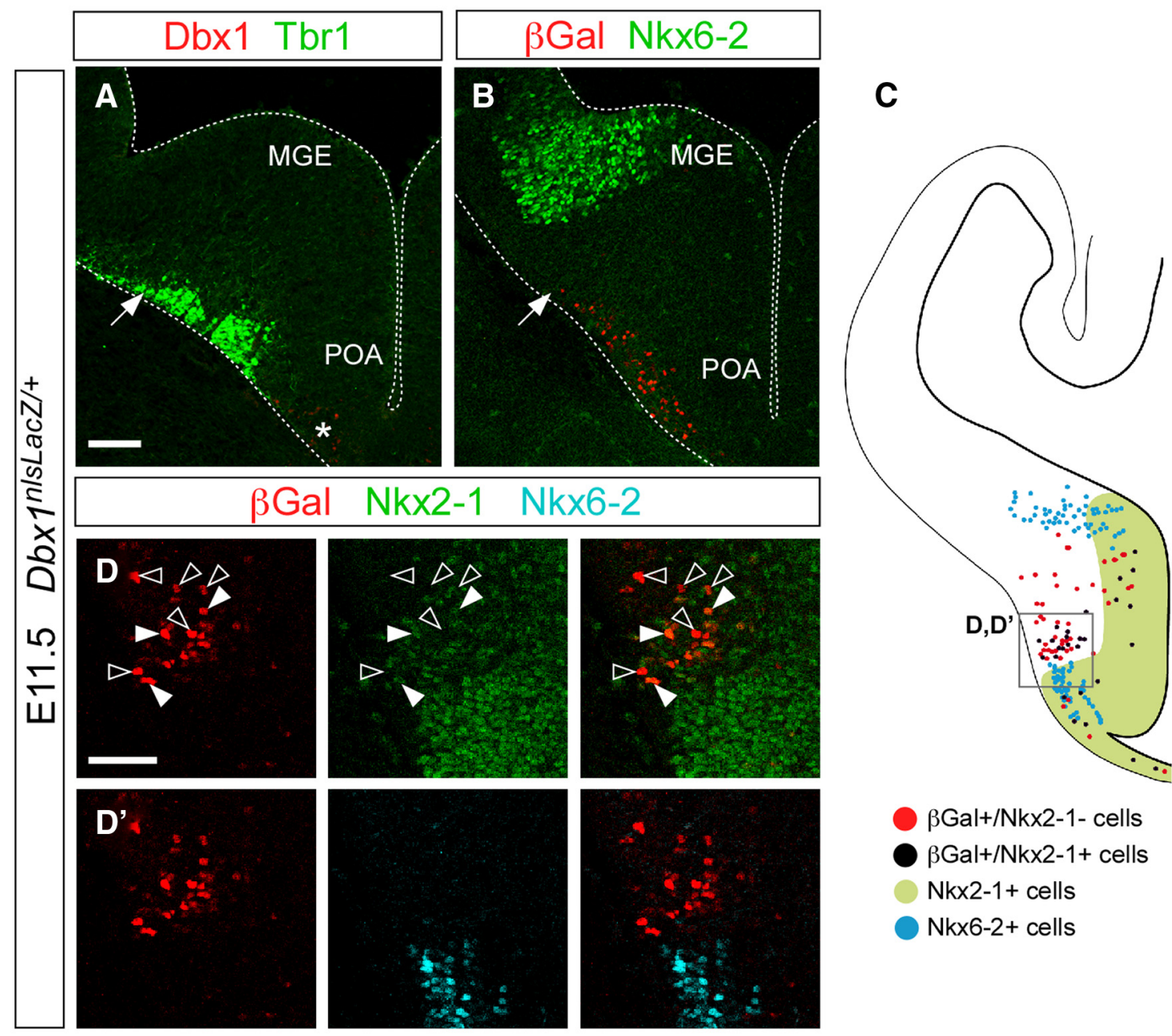

Figure 3. Molecular characterization of Dbx1-derived cells in the embryonic POA. $A, B, D, D^{\prime}$, Coronal sections through the telencephalon of E11.5 Dbx $7^{\text {nlsLacz/+ }}$ embryos showing the expression of Dbx1- $(\boldsymbol{A}), \boldsymbol{\beta G a l}-(\boldsymbol{B}, \boldsymbol{D}, \boldsymbol{D})$, Tbr1- $(\boldsymbol{A})$, Nkx6-2- ( $\boldsymbol{B}, \boldsymbol{D})$, and Nkx2-1- (D) expressing cells. The asterisk ( $\boldsymbol{A})$ indicates the location of Dbx1-expressing progenitor cells; the arrow in $\boldsymbol{B}$ denotes the extent of the migration of the cells derived from Dbx1-expressing progenitors at this stage. $\boldsymbol{D}$ and $\boldsymbol{D}^{\prime}$ are high-magnification images of the boxed area in $\boldsymbol{C}$. Filled arrowheads point to double-labeled cells; open arrowheads point to single-labeled cells. C, Schematic drawing of a hemisection through the telencephalon of an E11.5 mouse embryo showing the distribution of molecularly distinct populations of POA cells. Scale bars, $100 \mu \mathrm{m}$.

cortical territories. In coronal sections, a prominent strain of YFP-expressing cells was found in the pallial subventricular zone (Fig. $4 \mathrm{~A}$ ), one of the main routes followed by migrating interneurons (Lavdas et al., 1999; Marín and Rubenstein, 2001). Some YFP-expressing cells were also found in the marginal zone (MZ) (Fig. 4A). Immunohistochemical analyses demonstrated that many of the YFP-expressing cells found in the embryonic cortex contained GABA and calbindin, a marker of immature interneurons (Fig. $4 A^{\prime}-B^{\prime}$, and data not shown). Of note, the number of YFP-expressing cells invading the embryonic cortex declined significantly around E15.5 (Fig. 4D-E'), consistent with the early origin of this population of neurons (Fig. $1 E$ ). In addition, we observed that many YFP-expressing cells in the MZ contained CR (Fig. $4 C$ ), a finding that is in agreement with the notion that a population of Cajal-Retzius cells derive from Dbx1-expressing progenitors (Bielle et al., 2005).

We performed transplantation experiments to unequivocally demonstrate that Dbx1-derived cortical interneurons emerge from the embryonic POA. To this end, we prepared acute coronal slices through the telencephalon of E12.5 Dbx1 ${ }^{\mathrm{Cre}} ; \mathrm{ROSA} 26^{\mathrm{YFP}}$ embryos and isolated cells from the POA (Fig. 5A). We then used ultrasound imaging to transplant these cells into the POA of wild- type host embryos of the same age. Brains of transplanted embryos were analyzed at P14 for the distribution of YFP-expressing cells. We found YFP-expressing cells in the cortex of all host mice $(n=3$; Fig. $5 B)$, which demonstrated that Dbx1-derived cells born in the POA migrate to the cortex. In addition, we observed that nearly $70 \%$ of the YFP-expressing cells also contain GABA $(68.35 \pm 3.65 \%, n=100$ cells from three different brains; Fig. $\left.5 C, C^{\prime}\right)$. Altogether, these experiments demonstrate that the embryonic POA is the origin of the population of Dbx1-derived interneurons found in the cerebral cortex.

\section{Different classes of cortical interneurons derive from Dbx1-expressing progenitors}

To characterize the population of GABAergic interneurons that derives from Dbx1-expressing progenitor cells in the POA, we first investigated their molecular properties using different markers of the main classes of cortical interneurons. Although the neurochemical content does not represent an unequivocal criterion to classify cortical interneurons, previous studies in the mouse have shown that the expression of PV, SST, and VIP identify largely different populations of cortical interneurons (Kubota and Kawaguchi, 1994). A recent study has also shown that in- 


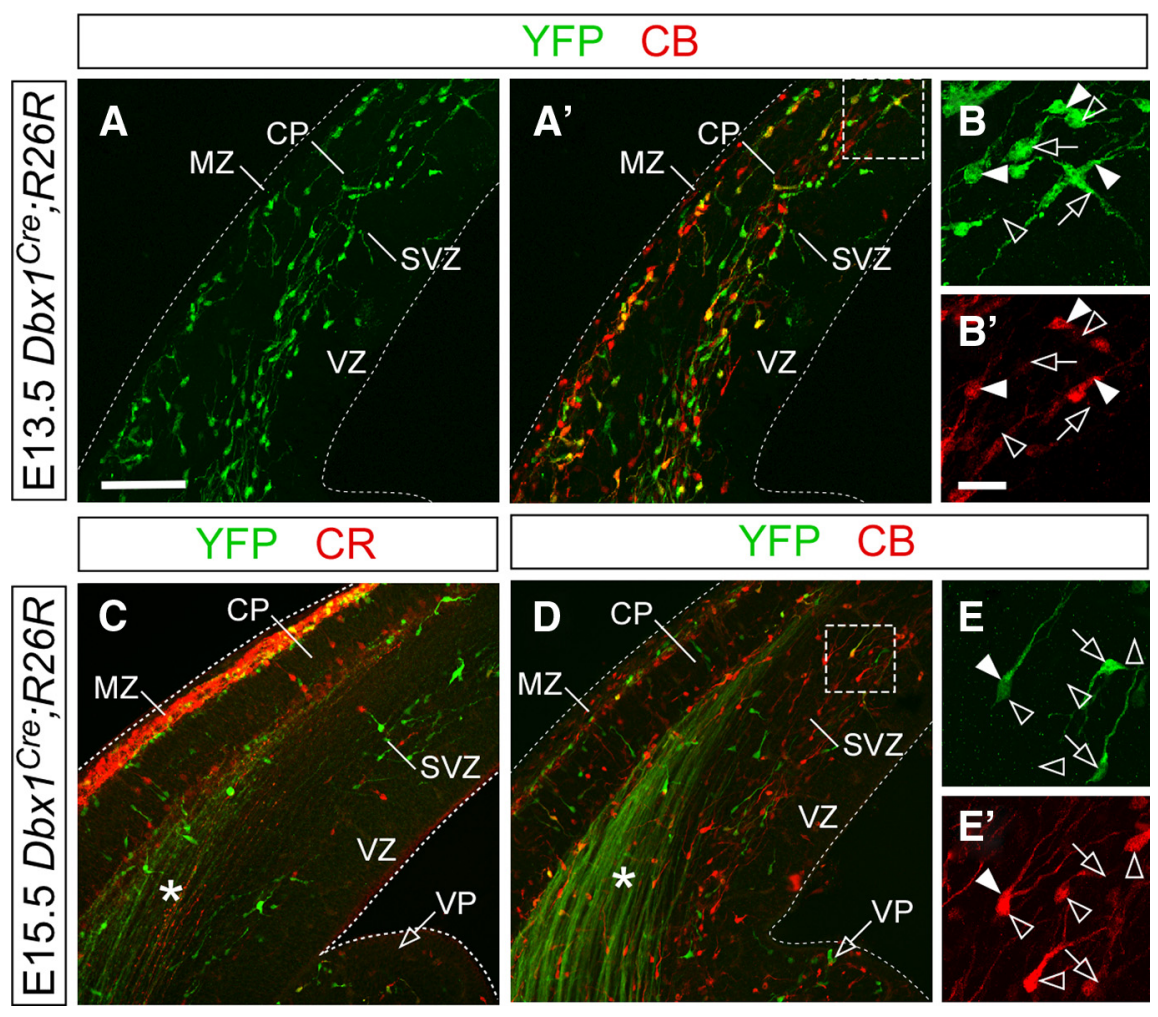

Figure 4. YFP expression in the developing telencephalon of $D b x 7^{\text {Cre }}, R O S A 26^{Y F P}$ embryos. $A-E^{\prime}$, Coronal sections through the

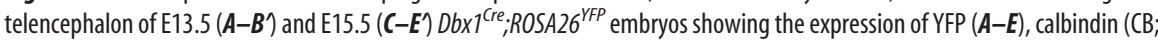
$\left.A^{\prime}, B^{\prime}, D, E^{\prime}\right)$, and $C R(C) . B, B^{\prime}$ and $E_{1}, E^{\prime}$, High-magnification images of the boxed areas in $\boldsymbol{A}^{\prime}$ and $\boldsymbol{D}$, respectively. $(P$, cortical plate; SVZ, subventricular zone; VZ, ventricular zone. Filled arrowheads point to double-labeled cells, open arrowheads point to calbindin +/YFP - cells; arrows point to calbindin - /YFP + cells. R26R, ROSA26 $6^{\text {YFP }}$. Scale bars: $A, A^{\prime}, C, D$ (in $A$ ), $100 \mu \mathrm{m} ; \boldsymbol{B}, \boldsymbol{B}^{\prime}, \boldsymbol{E}, \boldsymbol{E}^{\prime}$ (in B), $25 \mu \mathrm{m}$.

terneurons that contain the glycoprotein Reelin and lack SST belong to another non-overlapping population (Miyoshi et al., 2010). In P30 Dbx ${ }^{\text {Cre }}$;ROSA $26^{\text {YFP }}$ mice, nearly $50 \%$ of the POAderived YFP-expressing cortical interneurons found in the somatosensory cortex stained with antibodies against PV (48.81 \pm $6.7 \%, n=547$ cells from three different animals; Fig. 6 A, C, G,I). YFP-expressing interneurons containing SST or Reelin were also relatively abundant, respectively accounting for $\sim 25 \%$ and $\sim 15 \%$ of the Dbx1-derived interneurons found in the somatosensory cortex (SST: $21.9 \pm 6.3 \%$; Reelin: $14.8 \pm 3.7 \%, n=445$ and 921 cells, respectively, from three different animals; Fig. $6 B, C, E, G, I)$. In contrast, a very small percentage of neurons were found to express CR, NOS, or VIP (CR: $3.3 \pm 0.3 \%$; NOS: $2.3 \pm 0.8 \%$; VIP: $3.9 \pm 2.0 \%, n=445,302$, and 672 cells, respectively, from three different animals; Fig. $6 F-I)$, and none expressed NPY ( $n=402$ cells from three different animals; Fig. 6I,J).

Since many of the interneurons that derive from Dbx1expressing progenitors share features with interneurons derived from the MGE, and all these cells are thought to coexpress the transcription factor Lhx6 (Liodis et al., 2007), we analyzed the expression of this transcription in Dbx1-derived cortical interneurons. We found that two-thirds of the YFP-expressing cortical interneurons do not express Lhx6 (35.8 $\pm 5.9 \%, n=189$ cells from three different animals; Fig. $6 K$ ). This finding reinforced the notion that Dbx1-derived interneurons are molecularly distinct from those derived from the MGE.

\section{Analysis of the intrinsic physiological properties of}

\section{Dbx1-derived cortical interneurons}

To strengthen our conclusion that Dbx1expressing progenitor cells generate several distinct classes of cortical interneurons, we recorded the intrinsic properties of a total of 35 YFP-expressing interneurons in the somatosensory cortex of P17-P22 Dbx1 ${ }^{\text {Cre }}$;ROSA26 $6^{\text {YFP }}$ mice. Consistent with our molecular profiling, we classified Dbx1-derived cortical interneurons into several distinct subtypes based on their electrophysiological profile: FS, intrinsic and adapting bursting (IB and bAD, respectively), late-spiking (LS), and irregular-spiking (IS) cells.

The most abundant population of Dbx1-derived cortical interneurons belongs to the fast-spiking class $(51.4 \%, n=$ 18 of 35 cells). FS cells were characterized by a high MFF (mean: $151 \pm 13 \mathrm{~Hz} ; n=$ 18) with brief action potentials and deep AHP (Table 1), and little or no spike frequency adaptation during suprathreshold depolarizing current steps (mean percentage of adaptation: $10.2 \pm 5.7 \%, n=18$ cells; Fig. 7, Table 1). This population of cells corresponds to a morphologically diverse group of basket cells (Fig. 6D), which could be further segregated into two major populations based on the spiking at suprathreshold potentials: stuttering FS interneurons (sFS; $28.6 \%, n=10$ out 35 cells), which displayed a highfrequency firing pattern with random intervals of silence at suprathreshold potentials (Fig. 7, Table 1), and continuous FS cells (cFS; $22.9 \%, n=8$ of 35 cells), which had a steady and nonadapting firing pattern (Fig. 7, Table 1). It is worth mentioning that approximately a third of the FS cells ( 3 of $10 \mathrm{sFS}$ cells and 3 of $8 \mathrm{cFS}$ cells) also displayed a delay to the initial spike at near-threshold potentials $(296.5 \pm 48.6 \mathrm{~ms}$ compared with $25.1 \pm 10.2 \mathrm{~ms}$ for the nondelayed FS cells; $p=0.002, t$ test).

The second main population of Dbxl-derived cortical interneurons corresponds to non-fast-spiking, bAD/IB cells. This heterogeneous population of cells represented a quarter of all recorded cells $(25.7 \%, n=9$ of 35 cells). IB cells $(14.3 \%, n=5$ of 35 cells) were characterized by a burst of two or more action potentials when depolarizing from the resting membrane potential (Fig. 7). They also displayed a wide range of spike frequency adaptation at suprathreshold potentials (3-47\%; Table 1). Of note, the IB cells recorded in our study did not exhibit any rebound bursting during depolarization from resting membrane potential (Fig. 7). bAD cells ( $11.4 \%, n=4$ of 35 cells) were found to fire a small burst of two spikes above threshold (Fig. 7). They also showed a strong level of adaptation at suprathreshold potentials, with a relatively wide range of spike frequency (43-86\%; Table 1).

We also identified a small group of Dbx1-derived cells that belong to the LS subtype of cortical interneurons $(8.6 \%, n=3$ of $35)$. They displayed a delay to the initial spike at near-threshold current injections $(263.6 \pm 116.9 \mathrm{~ms})$ that was eliminated at suprathreshold potentials (Fig. 7). They also exhibit a pronounced firing frequency adaptation (Table 1). Finally, the last 
group of interneurons we identified in our analysis $(8.6 \%, n=3$ of 35$)$ showed IS firing during intermediate current steps and spike amplitude accommodation during suprathreshold current steps (Fig. 7, Table 1).

In addition to the major subtypes described above, we recorded two cells with adapting profiles, a continuous adapting cell $(2.9 \%, n=1$ of 35$)$ and a fast adapting (fAD) cell $(2.9 \%, n=1$ of 35$)$. The recorded fAD cell failed to fire throughout the $500 \mathrm{~ms}$ step during suprathreshold depolarization (data not shown).

In summary, our electrophysiological analysis reinforced the idea that the small progenitor domain of the embryonic POA characterized by the expression of Dbx1 is the origin of many distinct classes of cortical interneurons.

\section{Discussion}

The generation of neuronal diversity in the CNS seems intimately linked to the specification of progenitor cells at distinct locations within the neural tube. In the spinal cord, for example, the position of progenitor cells along the rostrocaudal and dorsoventral axes is thought to influence their fate by delimiting the concentration of inductive signals to which they are exposed (Jessell, 2000). In this model, transcription factors act as mediators of the inductive signals by translating graded responses into specific neural fates (Briscoe et al., 2000). In the telencephalon, a similar model has been adopted to explain the generation of cortical interneuron diversity. Accordingly, distinct classes of cortical interneurons have been shown to emerge from three of the main subdivisions of the subpallium: the MGE, the CGE, and the POA (Wonders and Anderson, 2006; Batista-Brito and Fishell, 2009; Gelman and Marín, 2010); each of these regions contains several pools of progenitor cells characterized by the expression of specific combinations of transcription factors (Flames et al., 2007). In this study, we report the existence of a previously unidentified pool of progenitor cells in the embryonic POA that give rise to a small fraction of cortical GABAergic interneurons. Intriguingly, this small population of progenitor cells seems to give rise to a large variety of cortical interneuron subtypes, which suggests that the mechanisms controlling the specification of GABAergic interneurons might be even more complex than previously anticipated.

\section{The POA is the third source of cortical GABAergic interneurons}

A large body of experimental evidence based on in vitro and in vivo experimental embryology, mouse genetics, and fate mapping studies suggests that $>90 \%$ of cortical GABAergic interneurons are generated-at least in the mouse-from two relatively large regions of the subpallium, the MGE and the CGE (Lavdas et al., 1999; Sussel et al., 1999; Wichterle et al., 2001; Nery et al., 2002; Xu et al., 2004; Butt et al., 2005; Fogarty et al., 2007; Miyoshi et al., 2010; Rubin et al., 2010). These studies have revealed that the MGE is the origin of most interneurons that express PV or SST, which together account for $>60 \%$ of cortical interneurons in rodents (Wonders and Anderson, 2006; Batista-Brito and Fishell, 2009; Gelman and Marín, 2010). They belong to multiple distinct classes of interneurons with different molecular, morphological, and electrophysiological properties, including Chandelier cells, different classes of basket cells, and Martinotti cells, among others. The CGE, in contrast, is the origin of $\sim 30 \%$ of cortical interneurons. CGE-derived interneurons in rodents are characterized by the expression of the serotonin receptor $3 \mathrm{~A}$ $\left(5\right.$ HTR $_{\mathrm{A}}$ ) (Lee et al., 2010; Vucurovic et al., 2010), but they also comprise several distinct subtypes, including bipolar/bitufted $\mathrm{VIP}+$ (and sometimes CR + ) neurons, as well as many neurogliaform cells and multipolar interneurons that frequently express NPY and/or Reelin (López-Bendito et al., 2004; Butt et al., 2005; Miyoshi et al., 2010).

Where do the remaining cortical interneurons come from? Using in utero electroporation and genetic fate mapping in the mouse, we previously showed that the embryonic POA gives rise to a small but distinct population of GABAergic cells that frequently express NPY or Reelin, and that account for $\sim 4 \%$ of the cortical interneurons (Gelman et al., 2009). These cells transitorily express the transcription factor $N k \times 5-1$ and seem to emerge from the most dorsal aspect of the POA, a domain that we termed pPOA1 (Flames et al., 2007). In this study, we used a genetic fate mapping approach to trace the progeny of Dbx1-expressing progenitor cells located in pPOA2, a region immediately adjacent to 

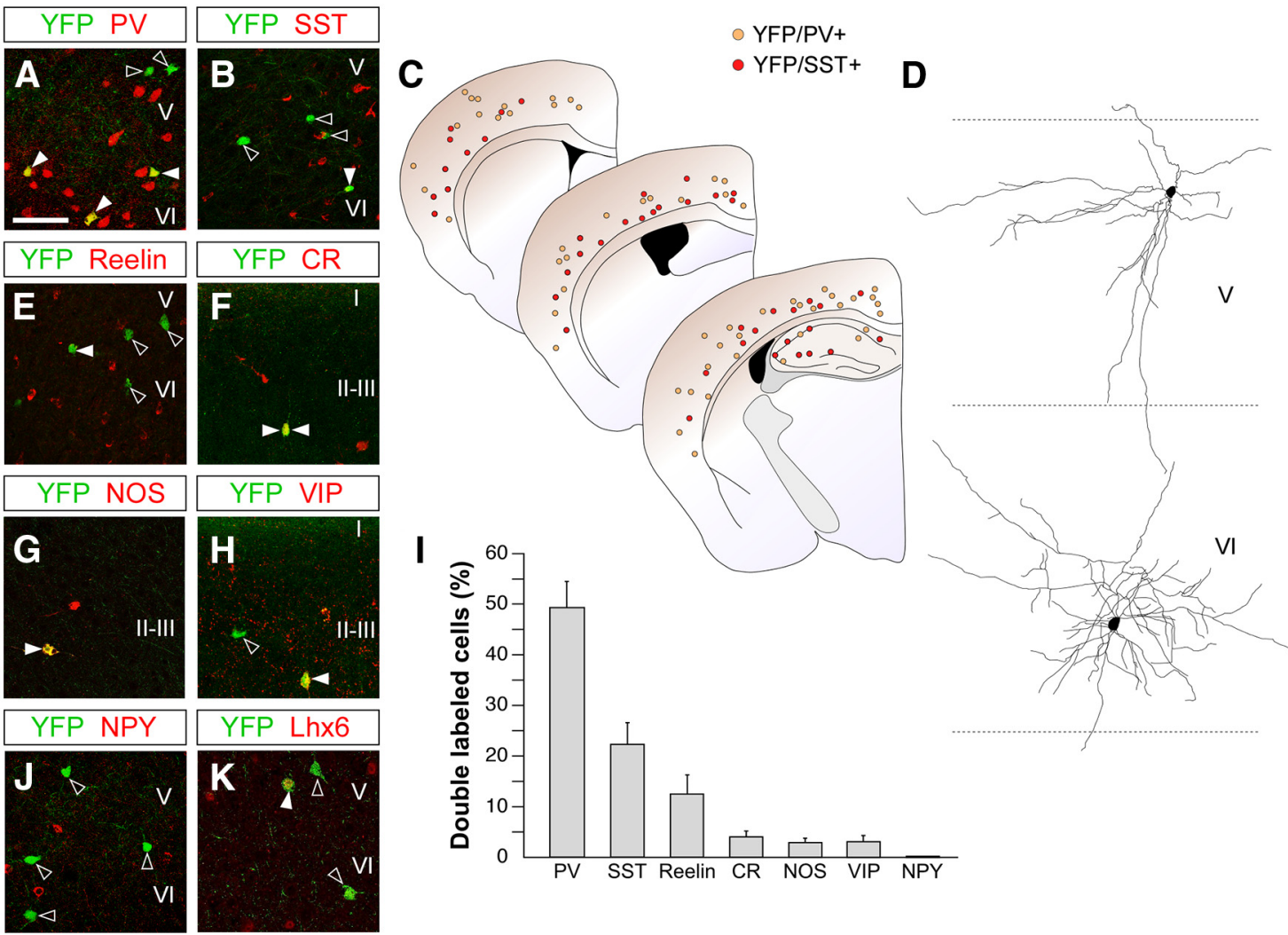

Figure 6. Neurochemical profile of cortical interneurons derived from Dbx1-expressing progenitor cells. $A, B, E, F, H, I$, Immunohistochemistry against $Y F P(A, B, E, F, H, I)$, parvalbumin $(A)$,

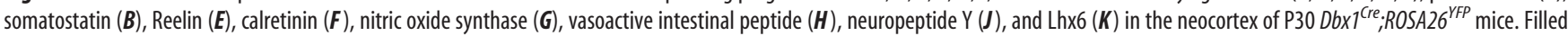
arrowheads point to double-labeled cells; open arrowheads indicate YFP-expressing neurons that do not express the corresponding marker. C, Schemas depicting the distribution of YFP-expressing interneurons containing PV (orange dots) or SST (red dots) in the neocortex and hippocampus of a P30 Dbx $7^{\text {Cre }} ; R O S A 26^{Y F P}$ mouse. D, Morphological varieties of FS cortical interneurons in $D b x 7^{\text {Cre }} ; R O S A 26^{Y F P}$ mice. The images are Neurolucida reconstructions from recorded neurons-a stuttering FS interneuron in layer V and a continuous FS interneuron in layer VI. $I$, Quantification of the percentage of colocalization of YFP-expressing cells with different neurochemical markers. Scale bar, $80 \mu \mathrm{m}$.

Table 1. Quantification of the electrophysiological properties of Dbx1-expressing interneurons in the somatosensory cortex

\begin{tabular}{|c|c|c|c|c|c|c|}
\hline & sFS & cFS & IB & bAD & LS & IS \\
\hline $\mathrm{RMP}(\mathrm{mV})$ & $-60.6 \pm 3.9$ & $-68.4 \pm 4.2$ & $-70.2 \pm 0.6$ & $-65.5 \pm 4.3$ & $-74.0 \pm 3.2$ & $-53.5 \pm 8.5$ \\
\hline $\mathrm{R}_{\mathrm{m}}(\mathrm{M} \Omega)$ & $125.1 \pm 22.4$ & $107.2 \pm 20.0$ & $142.2 \pm 24.9$ & $165.5 \pm 32.4$ & $142.7 \pm 58.6$ & $222.3 \pm 58.4$ \\
\hline$C_{m}(p F)$ & $18.1 \pm 3.6$ & $21.1 \pm 7.1$ & $7.1 \pm 0.8$ & $34.6 \pm 15.5$ & $6.4 \pm 2.5$ & $11.8 \pm 4.8$ \\
\hline APT (mV) & $-43.7 \pm 5.2$ & $-43.1 \pm 3.9$ & $-52.0 \pm 2.6$ & $-34.8 \pm 5.7$ & $-49.8 \pm 2.4$ & $-34.8 \pm 8.4$ \\
\hline $\mathrm{APA}(\mathrm{mV})$ & $51.8 \pm 4.0$ & $60.4 \pm 5.6$ & $65.9 \pm 10.5$ & $87.2 \pm 9.3$ & $70.7 \pm 2.6$ & $77.7 \pm 10.8$ \\
\hline APD (ms) & $0.49 \pm 0.05$ & $0.48 \pm 0.07$ & $0.99 \pm 0.12$ & $1.07 \pm 0.35$ & $1.43 \pm 0.12$ & $1.15 \pm 0.22$ \\
\hline $\operatorname{AHP}(\mathrm{mV})$ & $-16.2 \pm 1.3$ & $-19.2 \pm 1.3$ & $-13.9 \pm 4.0$ & $-10.3 \pm 2.0$ & $-12.3 \pm 1.8$ & $-8.8 \pm 1.3$ \\
\hline MFF (Hz) & $147.0 \pm 14.5$ & $155.3 \pm 25.8$ & $94.6 \pm 24.2$ & $26.0 \pm 2.4$ & $30.5 \pm 4.1$ & $35.0 \pm 6.2$ \\
\hline $\mathrm{Fr}_{1}(\mathrm{~Hz})$ & $108-488$ & $69-444$ & $67-526$ & $80-260$ & 54-194 & $101-214$ \\
\hline $\mathrm{Fr}_{\mathrm{SS}}(\mathrm{Hz})$ & $129-394$ & $56-370$ & $68-322$ & $32-48$ & $40-59$ & $60-76$ \\
\hline Freq. adaption (\%) & $17.0 \pm 8.0$ & $6.5 \pm 4.3$ & $25.8 \pm 8.8$ & $63.4 \pm 8.8$ & $36.8 \pm 16.5$ & $54.3 \pm 10.4$ \\
\hline Cells with Acc. & 1 of 10 & 1 of 8 & 2 of 5 & 2 of 4 & 1 of 3 & 3 of 3 \\
\hline$N$ & 10 & 8 & 5 & 4 & 3 & 3 \\
\hline
\end{tabular}

RMP, Resting membrane potential; $R_{m}$, membrane resistance; APT, action potential threshold; APA, action potential amplitude; $A P D$, action potential duration at its half amplitude; $A H P$, afterhyperpolarization amplitude; $C$, membrane capacitance; MFF, maximum firing frequency; $\mathrm{Fr}_{1}$, first spike frequency; $\mathrm{Fr}_{\mathrm{ss}}$, steady-state frequency; Freq. adaptation, spike frequency adaptation; Acc., accommodation. Cells not included are one continuous-adapting and one fast-adapting.

pPOA1. We found that this domain gives rise to yet another small population of cortical GABAergic interneurons $(\sim 4 \%)$ with molecular and electrophysiological features that are largely different from those observed in Nkx5-1-derived interneurons. It is worth noting that genetic fate mapping studies rely on the reliability of the expression of a single gene in a population of cells that are confined to a particular domain of the embryonic brain. In this particular case, expression of Dbx1 is not exclusively restricted to the POA, which is a possible confounding factor for tracing the progeny of these cells. However, several lines of evidence indicate that our interpretation of the fate mapping analysis of Dbx1derived interneurons is correct. First, we have previously shown with in utero electroporation that the POA gives rise to cortical GABAergic interneurons (Gelman et al., 2009). Second, our in utero transplantation experiments demonstrate that Dbx1expressing progenitor cells in the POA generate GABAergic interneurons that populate the cerebral cortex (Fig. 5). Some of these transplanted neurons were also found to express either PV 


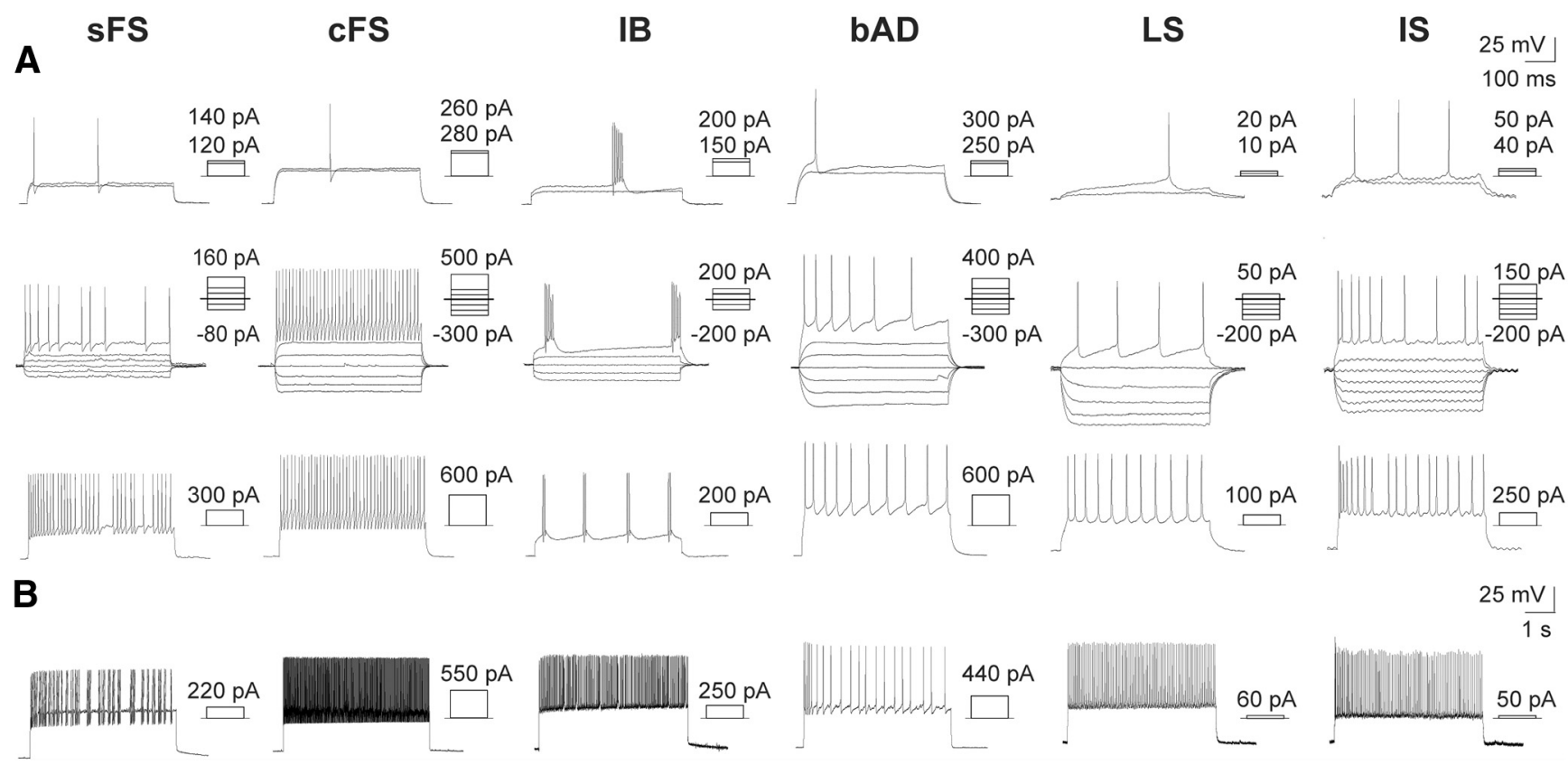

Figure 7. Intrinsic electrophysiological profiles of Dbx1-derived cortical interneurons. $\boldsymbol{A}$, Voltage responses to short depolarizing current injection (500 ms) at near-threshold (top), threshold (middle), and suprathreshold (bottom) potentials. $\boldsymbol{B}$, Voltage responses to prolonged step current injection ( $5 \mathrm{~s}$ ). Profiles are shown for an sFS interneuron, a cFS interneuron with delayed firing at near-threshold potentials, an IB interneuron that exhibits a burst of two to six spikes, a bAD interneuron that showed a burst of two spikes and a pronounced adaptation, an $L S$ interneuron, and an IS interneuron.

or SST (data not shown), although the large majority only stained for GABA. This might be due to the fact that many cells that are fated to become PV-expressing cells have not turned on the expression of this calcium-binding protein at P14, when we analyzed these experiments (Soriano et al., 1992). Third, the other regions containing Dbx1-expressing progenitors do not seem to produce GABAergic interneurons (Bielle et al., 2005; Rubin et al., 2010). Finally, it has been recently shown that a small fraction of $\mathrm{PV}+$ cortical interneurons derive from Shh-expressing cells in the subpallium (Flandin et al., 2010). Since Shh-expressing progenitor cells are confined to the caudoventral aspect of the MGE and the entire POA, these results reinforce the notion that a population of cortical interneurons derives from this later domain. In summary, our studies collectively suggest that the embryonic POA is the source of the nearly $10 \%$ of cortical interneurons that do not derive from the MGE or the CGE.

\section{The POA produces multiple classes of cortical GABAergic interneurons}

One of the most interesting findings of this study is that Dbx1expressing progenitor cells in the POA generate a great diversity of cortical GABAergic interneurons, even though they only represent a small fraction of the GABAergic neurons that populate the cortex. Indeed, this region of the embryonic POA seems to contribute to several of the major groups of cortical GABAergic interneurons: PV + FS basket cells, SST + bAD and IB cells, Reelin + and NOS + LS multipolar and neurogliaform interneurons, and VIP/CR + bipolar/bitufted IS cells. Furthermore, distinct subtypes can be recognized within some of these groups (e.g., delayed and nondelayed FS), which suggest that the diversity of interneuron classes that emerges from Dbxl-expressing progenitor cells is very large. Of note, Dbx1-derived neurons in the striatum also belong to several populations of interneurons, including cholinergic cells (45.9 $\pm 3.0 \%$ of the Dbx1-derived cells in the striatum, $n=97$ cells from three different animals) and all three major classes of GABAergic neurons $(43.8 \pm 3.9 \%$ of the Dbx1-derived cells in the striatum, $n=348$ cells from four different animals). Among these cells, Dbx1-derived interneurons are most abundant within the $\mathrm{PV}+$ population (representing $\sim 17 \%$ of the total population of PV + striatal interneurons). Thus, Dbx1-derived progenitors seem to be particularly capable of generating a large diversity of interneuron subtypes.

It is worth noting that Nkx5-1- and Dbx1-derived interneurons seem to belong to largely different groups, with perhaps only a minor overlap in the population of interneurons that express Reelin and have a continuous adapting electrophysiological profile ( 1 of 35 cells). This indicates that Nkx5-1-derived cells emerge from progenitor cells in the POA that do not express Dbx1.

Our findings suggest that the embryonic POA contributes to cortical interneuron populations that have been previously ascribed exclusively to the MGE or the CGE. Since POA progenitor cells are defined by a transcriptional program that is different from that found in the MGE and CGE, it would be expected that POA-derived interneurons have unique features that distinguish them from those generated in the other subpallial regions. For example, the POA seems to uniquely contribute to the population of PV + and SST + interneurons that colonize deep layers of the cortex, which therefore contain a mix of MGE- and POAderived interneurons. One factor that seems to distinguish the populations of cells from each other is Lhx6, which is expressed by MGE-derived interneurons (Lavdas et al., 1999; Fogarty et al., 2007), but is largely absent from POA-derived interneurons (Flames et al., 2007; Gelman et al., 2009; this study). Consistent with this idea, most PV + and SST + cortical interneurons (the MGE-derived population) are absent from the cortex of Lhx6 mutants, whereas some scattered PV + and SST + cells (the POAderived population) remain, primarily in deep layers of the cortex (Liodis et al., 2007; Zhao et al., 2008). As for other classes of interneurons, it is worth mentioning that $5 \mathrm{HTR} 3_{\mathrm{A}}$, a serotonin receptor that has been used to trace CGE-derived cortical in- 
terneurons, is also expressed in the dorsal aspect of the POA [identified as entopeduncular region by Vucurovic et al. (2010)]. Thus, although most NPY +, Reelin + and VIP/CR + bipolar/ bitufted IS cells derive from the CGE, a small fraction of these (in particular NPY + and Reelin + cells) also seem to emerge from different lineages within the POA (Gelman et al., 2009; this study).

\section{Transcriptional codes and cortical interneuron diversity}

Based on the model proposed for the spinal cord (Jessell, 2000), we and others have hypothesized that the different classes of cortical interneurons would emerge from relatively small populations of spatially restricted progenitor cells in the subpallium (Flames et al., 2007; Fogarty et al., 2007; Wonders et al., 2008; Batista-Brito and Fishell, 2009). Although it is likely that other factors such as temporal regulation influence the fate of subpallial progenitors (Miyoshi et al., 2007), it has been assumed that regional genetic patterning of the MGE, CGE, and POA is a prominent cause of cortical interneuron diversity. Inherent to this idea is the notion that different classes of interneurons arise from spatially segregated pools of progenitors, as is the case for the spinal cord. For example, PV + cortical interneurons are primarily generated in the ventral aspect of the MGE, while SST+ interneurons arise from its dorsal region (Flames et al., 2007; Wonders et al., 2008). Our findings indicate that this might not be the case, since some of these large groups of interneurons appear to derive from different types of progenitors. Obviously, it remains to be determined to what extent MGE- and POA-derived interneurons with similar features (e.g., PV+ FS basket cells) indeed belong to the same class of interneurons, because there may be distinguishing features not yet studied (e.g., afferent connections).

Considering the wide variety of interneurons that emerge from Dbx1-expressing progenitors, it is conceivable that this small pool of cells indeed consists of several classes of progenitors, each one of them expressing additional transcription factors that remain unidentified. Alternatively, our results might indicate that the same progenitor cells give rise to very different classes of interneurons (e.g., PV- and SST-expressing cells), a possibility that is consistent with previous transplantation experiments (Flames et al., 2007; Wonders et al., 2008). Clonal analyses of individual progenitor cells will be needed to elucidate this important question.

\section{References}

Anderson SA, Eisenstat DD, Shi L, Rubenstein JL (1997) Interneuron migration from basal forebrain to neocortex: dependence on Dlx genes. Science 278:474-476.

Ascoli GA, Alonso-Nanclares L, Anderson SA, Barrionuevo G, BenavidesPiccione R, Burkhalter A, Buzsáki G, Cauli B, Defelipe J, Fairén A, Feldmeyer D, Fishell G, Fregnac Y, Freund TF, Gardner D, Gardner EP, Goldberg JH, Helmstaedter M, Hestrin S, Karube F, et al. (2008) Petilla terminology: nomenclature of features of GABAergic interneurons of the cerebral cortex. Nat Rev Neurosci 9:557-568.

Batista-Brito R, Fishell G (2009) The developmental integration of cortical interneurons into a functional network. Curr Top Dev Biol 87:81-118.

Bielle F, Griveau A, Narboux-Nême N, Vigneau S, Sigrist M, Arber S, Wassef M, Pierani A (2005) Multiple origins of Cajal-Retzius cells at the borders of the developing pallium. Nat Neurosci 8:1002-1012.

Briscoe J, Pierani A, Jessell TM, Ericson J (2000) A homeodomain protein code specifies progenitor cell identity and neural fate in the ventral neural tube. Cell 101:435-445.

Butt SJ, Fuccillo M, Nery S, Noctor S, Kriegstein A, Corbin JG, Fishell G (2005) The temporal and spatial origins of cortical interneurons predict their physiological subtype. Neuron 48:591-604.
Corbin JG, Nery S, Fishell G (2001) Telencephalic cells take a tangent: nonradial migration in the mammalian forebrain. Nat Neurosci 4:1177-1182.

DeFelipe J (1997) Types of neurons, synaptic connections and chemical characteristics of cells immunoreactive for calbindin-D28K, parvalbumin and calretinin in the neocortex. J Chem Neuroanat 14:1-19.

Dessaud E, McMahon AP, Briscoe J (2008) Pattern formation in the vertebrate neural tube: a sonic hedgehog morphogen-regulated transcriptional network. Development 135:2489-2503.

Flames N, Pla R, Gelman DM, Rubenstein JL, Puelles L, Marín O (2007) Delineation of multiple subpallial progenitor domains by the combinatorial expression of transcriptional codes. J Neurosci 27:9682-9695.

Flandin P, Kimura S, Rubenstein JL (2010) The progenitor zone of the ventral medial ganglionic eminence requires $\mathrm{Nkx} 2-1$ to generate most of the globus pallidus but few neocortical interneurons. J Neurosci 30:2812-2823.

Fogarty M, Grist M, Gelman D, Marín O, Pachnis V, Kessaris N (2007) Spatial genetic patterning of the embryonic neuroepithelium generates GABAergic interneuron diversity in the adult cortex. J Neurosci 27:10935-10946.

Freund TF, Buzsáki G (1996) Interneurons of the hippocampus. Hippocampus 6:347-470.

Gelman DM, Marín O (2010) Generation of interneuron diversity in the mouse cerebral cortex. Eur J Neurosci 31:2136-2141.

Gelman DM, Martini FJ, Nóbrega-Pereira S, Pierani A, Kessaris N, Marín O (2009) The embryonic preoptic area is a novel source of cortical GABAergic interneurons. J Neurosci 29:9380-9389.

Griveau A, Borello U, Causeret F, Tissir F, Boggetto N, Karaz S, Pierani A (2010) A novel role for Dbx1-derived Cajal-Retzius cells in early regionalization of the cerebral cortical neuroepithelium. PLoS Biol 8:e1000440.

Hirata T, Li P, Lanuza GM, Cocas LA, Huntsman MM, Corbin JG (2009) Identification of distinct telencephalic progenitor pools for neuronal diversity in the amygdala. Nat Neurosci 12:141-149.

Jessell TM (2000) Neuronal specification in the spinal cord: inductive signals and transcriptional codes. Nat Rev Genet 1:20-29.

Kawaguchi Y, Kondo S (2002) Parvalbumin, somatostatin and cholecystokinin as chemical markers for specific GABAergic interneuron types in the rat frontal cortex. J Neurocytol 31:277-287.

Klausberger T, Somogyi P (2008) Neuronal diversity and temporal dynamics: the unity of hippocampal circuit operations. Science 321:53-57.

Kubota Y, Kawaguchi Y (1994) Three classes of GABAergic interneurons in neocortex and neostriatum. Jpn J Physiol 44 [Suppl 2]:S145-S148.

Lavdas AA, Grigoriou M, Pachnis V, Parnavelas JG (1999) The medial ganglionic eminence gives rise to a population of early neurons in the developing cerebral cortex. J Neurosci 19:7881-7888.

Lee SK, Pfaff SL (2001) Transcriptional networks regulating neuronal identity in the developing spinal cord. Nat Neurosci 4 [Suppl]:1183-1191.

Lee S, Hjerling-Leffler J, Zagha E, Fishell G, Rudy B (2010) The largest group of superficial neocortical GABAergic interneurons expresses ionotropic serotonin receptors. J Neurosci 30:16796-16808.

Liodis P, Denaxa M, Grigoriou M, Akufo-Addo C, Yanagawa Y, Pachnis V (2007) Lhx6 activity is required for the normal migration and specification of cortical interneuron subtypes. J Neurosci 27:3078-3089.

López-Bendito G, Sturgess K, Erdélyi F, Szabó G, Molnár Z, Paulsen O (2004) Preferential origin and layer destination of GAD65-GFP cortical interneurons. Cereb Cortex 14:1122-1133.

Marín O, Rubenstein JL (2001) A long, remarkable journey: tangential migration in the telencephalon. Nat Rev Neurosci 2:780-790.

Markram H, Toledo-Rodriguez M, Wang Y, Gupta A, Silberberg G, Wu C (2004) Interneurons of the neocortical inhibitory system. Nat Rev Neurosci 5:793-807.

Medina L, Legaz I, González G, De Castro F, Rubenstein JL, Puelles L (2004) Expression of Dbx1, Neurogenin 2, Semaphorin 5A, Cadherin 8, and Emxl distinguish ventral and lateral pallial histogenetic divisions in the developing mouse claustroamygdaloid complex. J Comp Neurol 474:504-523.

Miyoshi G, Butt SJ, Takebayashi H, Fishell G (2007) Physiologically distinct temporal cohorts of cortical interneurons arise from telencephalic Olig2expressing precursors. J Neurosci 27:7786-7798.

Miyoshi G, Hjerling-Leffler J, Karayannis T, Sousa VH, Butt SJ, Battiste J, Johnson JE, Machold RP, Fishell G (2010) Genetic fate mapping reveals that the caudal ganglionic eminence produces a large and diverse population of superficial cortical interneurons. J Neurosci 30:1582-1594.

Nery S, Fishell G, Corbin JG (2002) The caudal ganglionic eminence is a 
source of distinct cortical and subcortical cell populations. Nat Neurosci 5:1279-1287.

Nóbrega-Pereira S, Kessaris N, Du T, Kimura S, Anderson SA, Marín O (2008) Postmitotic Nkx2-1 controls the migration of telencephalic interneurons by direct repression of guidance receptors. Neuron 59:733-745.

Pierani A, Moran-Rivard L, Sunshine MJ, Littman DR, Goulding M, Jessell TM (2001) Control of interneuron fate in the developing spinal cord by the progenitor homeodomain protein Dbx1. Neuron 29:367-384.

Pla R, Borrell V, Flames N, Marín O (2006) Layer acquisition by cortical GABAergic interneurons is independent of Reelin signaling. J Neurosci 26:6924-6934.

Rubin AN, Alfonsi F, Humphreys MP, Choi CK, Rocha SF, Kessaris N (2010) The germinal zones of the basal ganglia but not the septum generate GABAergic interneurons for the cortex. J Neurosci 30:12050-12062.

Somogyi P, Klausberger T (2005) Defined types of cortical interneurone structure space and spike timing in the hippocampus. J Physiol 562:9-26.

Soriano E, Del Rio JA, Ferrer I, Auladell C, De Lecea L, Alcantara S (1992) Late appearance of parvalbumin-immunoreactive neurons in the rodent cerebral cortex does not follow an 'inside-out' sequence. Neurosci Lett 142:147-150.

Srinivas S, Watanabe T, Lin CS, William CM, Tanabe Y, Jessell TM, Costantini F (2001) Cre reporter strains produced by targeted insertion of EYFP and ECFP into the ROSA26 locus. BMC Dev Biol 1:4.

Sussel L, Marín O, Kimura S, Rubenstein JL (1999) Loss of Nkx2.1 homeobox gene function results in a ventral to dorsal molecular respecification within the basal telencephalon: evidence for a transformation of the pallidum into the striatum. Development 126:3359-3370.

Teissier A, Griveau A, Vigier L, Piolot T, Borello U, Pierani A (2010) A novel transient glutamatergic population migrating from the pallial-subpallial boundary contributes to neocortical development. J Neurosci 30:1056310574.

Teissier A, Waclaw RR, Griveau A, Campbell K, Pierani A (2011) Tangentially migrating transient glutamatergic neurons control neurogenesis and maintenance of cerebral cortical progenitor pools. Cereb Cortex. Advance online publication. doi:10.1093/cercor/bhr122.

Vucurovic K, Gallopin T, Ferezou I, Rancillac A, Chameau P, van Hooft JA, Geoffroy H, Monyer H, Rossier J, Vitalis T (2010) Serotonin 3A receptor subtype as an early and protracted marker of cortical interneuron subpopulations. Cereb Cortex 20:2333-2347.

Wichterle H, Garcia-Verdugo JM, Herrera DG, Alvarez-Buylla A (1999) Young neurons from medial ganglionic eminence disperse in adult and embryonic brain. Nat Neurosci 2:461-466.

Wichterle H, Turnbull DH, Nery S, Fishell G, Alvarez-Buylla A (2001) In utero fate mapping reveals distinct migratory pathways and fates of neurons born in the mammalian basal forebrain. Development 128:3759-3771.

Wonders CP, Anderson SA (2006) The origin and specification of cortical interneurons. Nat Rev Neurosci 7:687-696.

Wonders CP, Taylor L, Welagen J, Mbata IC, Xiang JZ, Anderson SA (2008) A spatial bias for the origins of interneuron subgroups within the medial ganglionic eminence. Dev Biol 314:127-136.

Xu Q, Cobos I, De La Cruz E, Rubenstein JL, Anderson SA (2004) Origins of cortical interneuron subtypes. J Neurosci 24:2612-2622.

Yun K, Potter S, Rubenstein JL (2001) Gsh2 and Pax6 play complementary roles in dorsoventral patterning of the mammalian telencephalon. Development 128:193-205.

Zhao Y, Flandin P, Long JE, Cuesta MD, Westphal H, Rubenstein JL (2008) Distinct molecular pathways for development of telencephalic interneuron subtypes revealed through analysis of Lhx6 mutants. J Comp Neurol 510:79-99. 